\title{
A Salomé, de Bruno Bravo Um espectáculo de poesia
}

\section{Rui Monteiro}
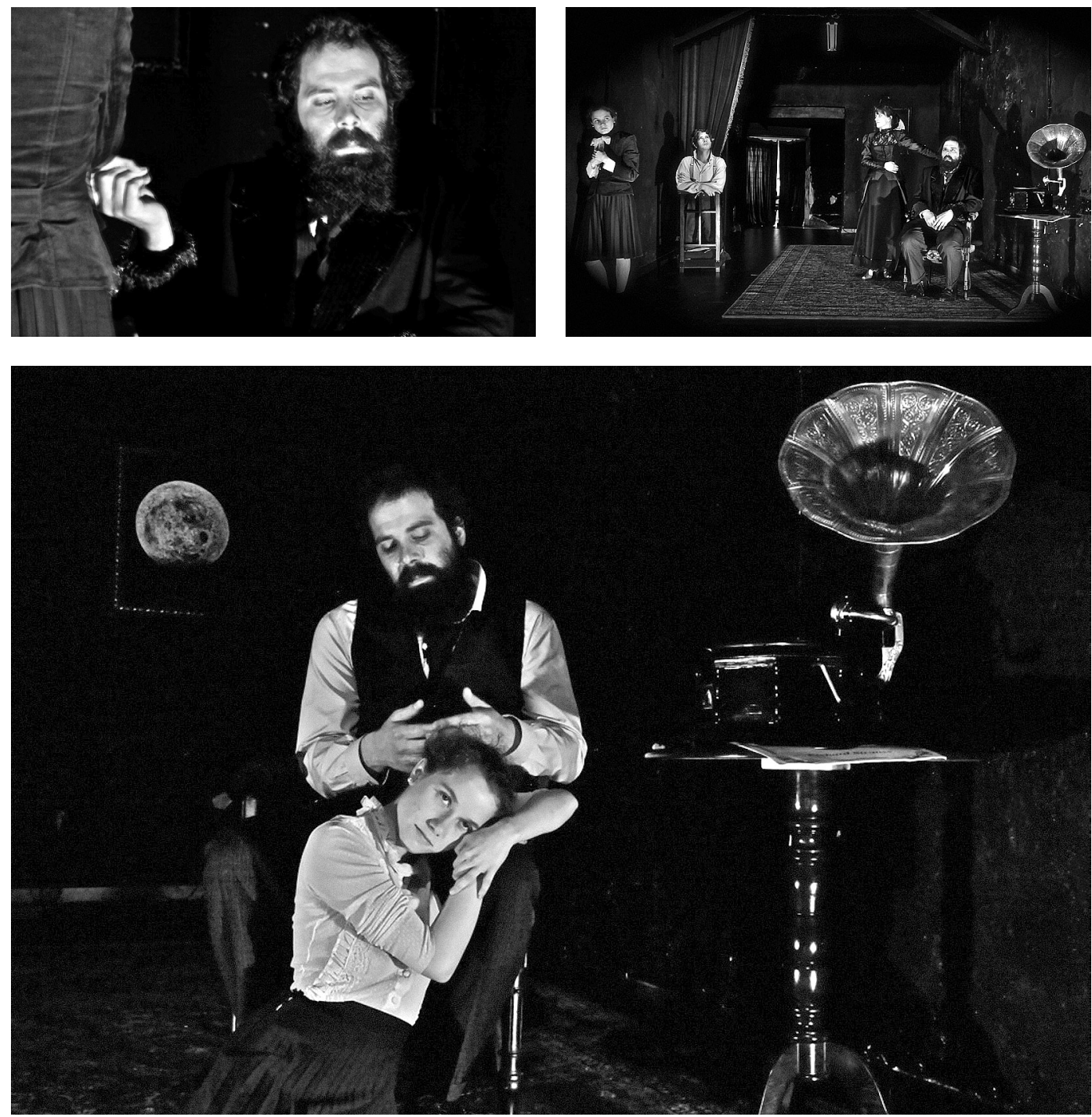

de Oscar Wilde,

enc. Bruno Bravo,

Primeiros Sintomas, 2012

< António Mortágua;

$>$ Carolina Salles,

Ricardo Neves-Neves,

Sandra Faleiro

e António Mortágua:

António Mortágua

e Carolina Salles),

fot. Bruno Bravo.

Há sempre duas versões: Oscar Wilde, o autor de Salomé, acha que São João Baptista teve a cabeça separada do corpo por mor da luxúria apaixonada da filha de Herodías.

Ora quem: precisamente quem, para a Biblia, por conta de um ódio igualmente apaixonado e uma manha sibilina é a matadora do profeta, pelo menos de um ponto de vista estritamente moral?

Bruno Bravo, o encenador, o inventor desta leitura da peça, produzida pela companhia Primeiros Sintomas, seguiu a primeira. E criou um espectáculo de sangue, suor, lágrimas, sexo; mas, sobretudo, criou um espectáculo de poesia.
Montando uma versão imaginativamente erótica e lírica da obra, sobre o ambiente húmido e vicioso, espesso como nevoeiro cerrado, nascido da cenografia de Stéphane Alberto, esculpido em luz por João Paiva, assombrado por palavras alimentadas por um desejo subversivo e belo, sublinhado na banda sonora de Sérgio Delgado, Bruno Bravo organiza a acção, em grande fidelidade à letra do texto, traduzido com brio por Aníbal Fernandes, como quem prepara uma visita guiada a lugar profundo como as masmorras de um castelo, ou esconso como os meandros da consciência. 


\section{Salomé,
de Oscar Wilde,
enc. Bruno Bravo, Primeiros Sintomas, 2012 \\ (Carolina Salles e Ricardo Neves-Neves),}

fot. Bruno Bravo.

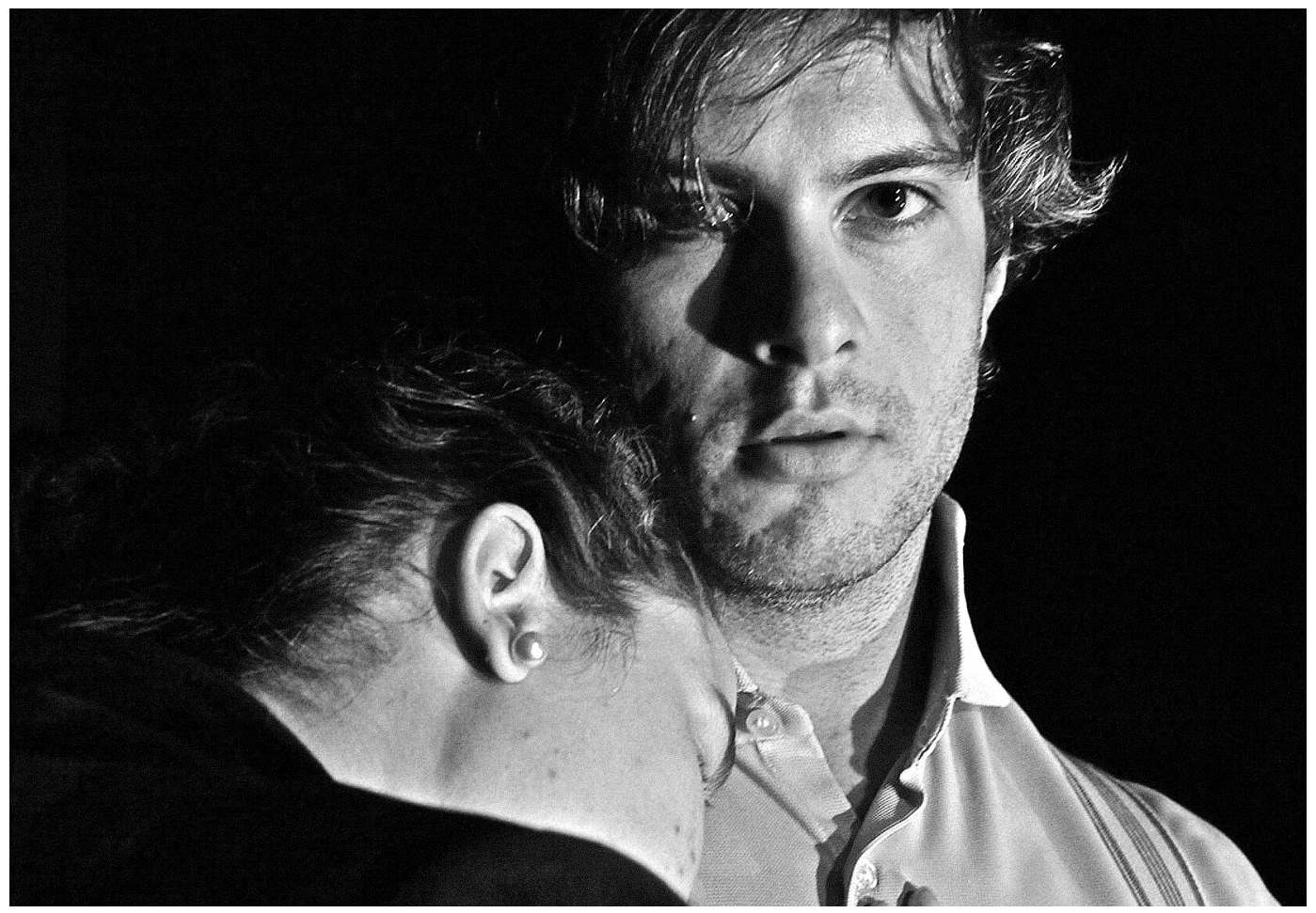

Uma ousada, direi, quase subversiva interpretação das regras dramáticas coloca Salomé em território fantasmático, para o que muito conta o notável desempenho de Carolina Salles. Salomé juvenilmente arrebatada pela paixão e pelo desejo do corpo interdito, a jovem actriz desenha com precisão uma criatura manipulável apenas na medida dos seus interesses de manipulação; perversa e doce, no entanto, conhecedora do poder de um corpo jovem e belo e de uma alma disposta a tudo. Por isso, personagem incapaz de se intimidar perante a lascivia repulsiva de Herodes e a influência interesseira e impiedosa de Herodias e artista, embora praticamente estreante, que não teme o convivio em palco com a intensidade de António Mortágua nem com a presença espectral e dominadora de Sandra Faleiro, representando entre a fragilidade e a mais fria crueldade como quem levita o vício nesta expedição a um lugar sonhado à maneira de parque de diversões da frustração da carne e da decadência do espírito - assim dando à Associação Portuguesa de Críticos de Teatro a oportunidade de atribuir esta Menção Especial. 